\title{
Nation-Wide Observational Study of Cardiac Arrests Occurring in Nursing Homes and Nursing Facilities in Singapore
}

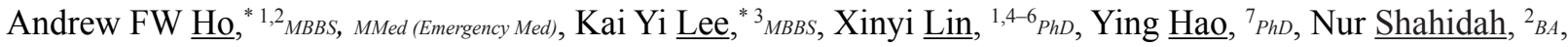
Yih Yng Ng, ${ }^{8}$ MBBS, MPH, Benjamin SH Leong, ${ }^{9}$ MBBS, MMed (Emergency Med), Ching-Hui Sia, ${ }^{10}$ MBBS, MMed (Int Med), MRCP (UK), Benjamin YQ Tan, ${ }^{11}{ }_{M B B S}$, Ai Meng Tay, ${ }^{12}{ }_{B B M}(H R)$, Marie XR Ng, ${ }^{12}$ MPH, Han Nee Gan, ${ }^{13}$ MBBS, MMed (Emergency Med), Desmond R Mao, ${ }^{14}$ MBBS, Michael YC $\underline{\text { Chia }},{ }^{8}$ MBBS, Si Oon $\underline{\text { Cheah }},{ }^{15}$ MBBS, Marcus EH Ong, ${ }^{1,2}$ MBBS, MPH

\begin{abstract}
Introduction: Nursing home (NH) residents with out-of-hospital cardiac arrests (OHCA) have unique resuscitation priorities. This study aimed to describe OHCA characteristics in $\mathrm{NH}$ residents and identify independent predictors of survival. Materials and Methods: OHCA cases between 2010-16 in the Pan-Asian Resuscitation Outcomes Study were retrospectively analysed. Patients aged $<18$ years old and non-emergency cases were excluded. Primary outcome was survival at discharge or 30 days. Good neurological outcome was defined as a cerebral performance score between 1-2. Results: A total of 12,112 cases were included. Of these, $449(3.7 \%)$ were NH residents who were older (median age 79 years, range 69-87 years) and more likely to have a history of stroke, heart and respiratory diseases. Fewer NH OHCA had presumed cardiac aetiology $(62 \%$ vs $70 \%, P<0.01)$ and initial shockable rhythm $(8.9 \%$ vs $18 \%, P<0.01)$, but had higher incidence of bystander cardiopulmonary resuscitation $(74 \%$ vs $43 \%, P<0.01)$ and defibrillator use $(8.5 \%$ vs $2.8 \%, P<0.01)$. Non-NH $(2.8 \%)$ residents had better neurological outcomes than NH $(0.9 \%)$ residents $(P<\mathbf{0 . 0 5})$. Factors associated with survival for cardiac aetiology included age $<65$ years old, witnessed arrest, bystander defibrillator use and initial shockable rhythm; for non-cardiac aetiology, these included witnessed arrest (adjusted odds ratio [AOR] 3.8, $P<0.001$ ) and initial shockable rhythm (AOR 5.7, $P<\mathbf{0 . 0 0 1 )}$. Conclusion: Neurological outcomes were poorer in NH survivors of OHCA. These findings should inform health policies on termination of resuscitation, advance care directives and do-not-resuscitate orders in this population.
\end{abstract}

Ann Acad Med Singapore 2020;49:285-93

Key words: Advance care directives, Do-not-resuscitate orders, Geriatrics, Out-ofhospital, Palliative care

\footnotetext{
${ }^{1}$ Health Services and Systems Research, Duke-NUS Medical School, Singapore

${ }^{2}$ Department of Emergency Medicine, Singapore General Hospital, Singapore

${ }^{3}$ Yong Loo Lin School of Medicine, National University of Singapore, Singapore

${ }^{4}$ Centre for Quantitative Medicine, Duke-NUS Medical School, Singapore

${ }^{5}$ Singapore Clinical Research Institute, Singapore

${ }^{6}$ Singapore Institute for Clinical Sciences, A"STAR, Singapore

${ }^{7}$ Health Services Research Unit, Division of Medicine, Singapore General Hospital, Singapore

${ }^{8}$ Emergency Department, Tan Tock Seng Hospital, Singapore

${ }^{9}$ Emergency Medicine Department, National University Hospital, Singapore

${ }^{10}$ Department of Cardiology, National University Heart Centre Singapore, Singapore

${ }^{11}$ Division of Neurology, Department of Medicine, National University Health System, Singapore

${ }^{12}$ Emergency Medical Services Department, Singapore Civil Defence Force, Singapore

${ }^{13}$ Accident \& Emergency Department, Changi General Hospital, Singapore

${ }^{14}$ Department of Acute and Emergency Care, Khoo Teck Puat Hospital, Singapore

${ }^{15}$ Emergency Medicine Department, Ng Teng Fong General Hospital, Singapore

*Both authors contributed equally to the design of the study and writing of the manuscript.

Address for Correspondence: Dr Andrew Ho Fu Wah, SingHealth Duke-NUS Emergency Medicine Clinical Academic Programme, c/o Department of Emergency Medicine, Singapore General Hospital, Outram Road, Singapore 169608.

Email: sophronesis@gmail.com
} 


\section{Introduction}

Out-of-hospital cardiac arrest (OHCA) is a significant public health problem in Singapore and from around the world. ${ }^{1}$ Between 2010-12, local OHCA patients with a witnessed arrest and shockable rhythm had a survival-to-hospital discharge rate of $11.0 \%{ }^{2}$ Treatment of OHCA patients is resource-intensive since it requires invasive interventions and potentially prolonged intensive care unit stays. ${ }^{3}$

Previous studies had reported that nursing homes $(\mathrm{NH})$ and nursing facilities are common sites of OHCA. ${ }^{4,5}$ Although OHCA outcomes have improved over the years, this is not the case in NH residents who continue to present with poor prognosis. ${ }^{4,5}$ There were suggestions that attempts at resuscitation are futile, with data showing few OHCA survivors in $\mathrm{NH}$ residents. ${ }^{6}$ However, studies also found that for witnessed arrests and shockable primary rhythm, survival rates were comparable in $\mathrm{NH}$ residents and elderly patients in the community. ${ }^{7,8}$ Some authors had suggested that OHCA in $\mathrm{NH}$ residents might have received bystander cardiopulmonary resuscitation (CPR) against their will since healthcare providers were unaware of their care preferences and care goals. ${ }^{9}$ Consequently, it is important to examine this group of OHCA patients to identify those who would benefit from resuscitation attempts and to guide decisions such as conveyance to hospital or termination of resuscitation. ${ }^{10,11}$ This study aimed to describe the characteristics and outcomes of OHCA in $\mathrm{NH}$ residents and identify independent predictors of survival.

\section{Materials and Methods}

Data from Singapore in the Pan-Asian Resuscitation Outcomes Study (PAROS) were used. Established in 2010, PAROS is a prospective, multi-centre registry that was designed to inform OHCA epidemiology and outcomes, describe variations among emergency medical services (EMS) and structural interventions in the Asia-Pacific region, primarily from Southeast Asia, South Asia, East Asia and Oceania. ${ }^{3}$ The methodology of PAROS was described in a previous study. ${ }^{12}$ Data definitions were based on the Utstein recommendations ${ }^{13}$ and collaboration with the Cardiac Arrest Registry to Enhance Survival ${ }^{14}$ in the United States that generated a unified taxonomy and data dictionary to facilitate valid global comparisons.

Patients aged $>18$ years old who were treated for OHCA by EMS between April 2010-December 2016 were included. Determinants of OHCA included absence of pulse, unresponsiveness and apnoea.
Patients who were pronounced dead at the scene were excluded, as were rare cases of irreversible death such as decapitation. This study was approved by the Centralised Institutional Review Board and Domain Specific Review Board with a waiver of patient consent.

Data were extracted from various sources that included emergency dispatch records, ambulance case notes and emergency department (ED) and in-hospital records. The details included location of arrest, witnessed arrest, bystander CPR, prehospital defibrillation and response times. $\mathrm{NH}$ OHCA was defined as arrests that occurred in $\mathrm{NH}$; non$\mathrm{NH}$ OHCA referred to arrests that occurred in other locations such as private residential homes. Aetiologies of cardiac arrest were determined from inpatient discharge summary records or coroner's reports in those who died in ED.

Primary outcome was survival to discharge or at 30 days. Secondary endpoints included neurological outcomes at discharge or 30 days, and were measured on Glasgow-Pittsburgh cerebral performance categories (CPC) and overall performance categories (OPC) for cerebral performance capabilities and both cerebral and physical performance capabilities, respectively. Neurological outcomes were assessed by the attending physician/team either at discharge or at 30 days. Return of spontaneous circulation (ROSC) was defined as either on site, en-route or in ED.

Data analysis was performed using SPSS Statistics for Windows, Version 25.0 (IBM Corp., Armonk, NY, USA). Categorical variables were expressed as frequency and percentages; continuous variables were expressed as median and interquartile range (IQR). Cases with missing data were excluded from analysis. Mann-Whitney $\mathrm{U}$ test was used to compare arrests that occurred in NH and non-NH locations; categorical variables were compared using Fisher's Exact test. Logistic regression was used to examine factors associated with survival to discharge or at 30 days.

Univariate and multivariate logistic regression was used to analyse cardiac and non-cardiac aetiologies. Non-cardiac aetiologies included respiratory conditions, electrocution, drowning and other causes such as cancer and renal disease. Covariates were determined based on a literature review of possible confounders and/or known prognostic factors, ${ }^{15-19}$ and were adjusted for in regression analyses. For presumed cardiac and non-cardiac aetiologies, 2 multivariate models were constructed to reflect postulated differences in incidence of aetiologies in $\mathrm{NH}$ and non-NH groups and different prognosticating factors. 


\section{Results}

Of the 12,546 OHCA cases identified by PAROS, 12,112 OHCA cases qualified for analysis. A total of 434 cases were excluded due to missing data. In terms of location, 449 (3.7\%) OHCA cases occurred in NH and 11,846 (96.3\%) in other locations. A flow chart of the patient selection process is shown in Figure 1.

Baseline characteristics of OHCA cases are shown in Table 1. NH residents (median age 79 years, IQR 69-87 years) were older than non-NH residents (median age 67 years, IQR 55-79 years, $P<0.01$ ) and were more likely to be women $(41 \%$ vs $35 \%$, $P<0.01)$ with a history of stroke $(34 \%$ vs $12 \%, P<0.01)$, heart disease $(43 \%$ vs $37 \%, P<0.01)$, respiratory disease $(17 \%$ vs $12 \%, P<0.01)$, hypertension ( $66 \%$ vs $54 \%, P<0.01)$ and hyperlipidaemia $(45 \%$ vs $37 \%$, $P<0.01)$. NH OHCA cases were less likely to have cardiac aetiologies $(62 \%$ vs $71 \%, P<0.01)$, initial shockable rhythm $(8.9 \%$ vs $18 \%, P<0.01)$ or prehospital defibrillation ( $14 \%$ vs $27 \%, P<0.01)$.

Patient outcomes and resuscitation factors are summarised in Table 2. NH OHCA cases had more bystander CPR (74\% vs 43\%, $P<0.01)$ and automated external defibrillator (AED) use (8.5\% vs $2.8 \%$, $P<0.01)$. Response time of EMS and scene time were shorter in NH OHCA cases (median time $7.7 \mathrm{~min}$, IQR 6.0-10.0 $\mathrm{min}$ and $15.7 \mathrm{~min}, \mathrm{IQR} 12.9-19.8 \mathrm{~min}$, respectively) than non-NH OHCA cases $(8.7 \mathrm{~min}$, IQR 6.7-11.3 $\mathrm{min}$ and $17.1 \mathrm{~min}$, IQR $13.8-21.0 \mathrm{~min}$, respectively). Median time to AED in NH OHCA cases was $4.0 \mathrm{~min}$ (IQR 2.9-5.6 $\mathrm{min}$ ) compared to $4.6 \mathrm{~min}$ (IQR 3.2-6.5 $\mathrm{min}$ ) in OHCA in other locations.

In this study, $4012(33.1 \%)$ cases attained ROSC, $528(4.4 \%)$ survived to discharge or at 30 days and $326(2.7 \%)$ survived with favourable neurological outcomes (Table 2). NH OHCA cases had lower survival at admission than non-NH OHCA cases $(11 \%$ vs $18 \%, P<0.01)$, and only $4(0.9 \%)$ of them achieved good neurological outcomes. They also had poorer scores on CPC $(0.9 \%$ vs $2.8 \%, P<0.05)$ and $\mathrm{OPC}$ $(0.9 \%$ vs $2.7 \%, P<0.05)$. In the 4 cases with good neurological outcomes, their median age was $<79$ years old and all of them attained ROSC en-route to ED and were witnessed arrests.

For OHCA with presumed cardiac and non-cardiac aetiologies, results of regression analyses of survival to discharge or at 30 days are shown in Table 3. Witnessed arrest and initial shockable rhythm were associated with survival in both cardiac and non-cardiac aetiologies. For witnessed arrest, the adjusted odds ratio (AOR) was 2.4 (95\% CI 1.8-3.2) and 3.8 (95\% CI 2.2-6.5) in cardiac and non-cardiac aetiologies, respectively. For initial shockable rhythm, likelihood of survival was higher when aetiology was attributed to cardiac (AOR 12.7, 95\% CI 9.8-16.7) than non-cardiac (AOR 5.7, 95\% CI 3.5-9.3) causes. Other factors that were associated with survival in OHCA from cardiac aetiology included age $\geq 65$ years old (AOR 0.61, 95\% CI 0.49-0.77) and bystander AED (AOR 2.4, 95\% CI 1.6-3.5), but NH location was not associated with survival in both.

\section{Discussion}

In this secondary analysis of a prospective national $\mathrm{OHCA}$ registry, $\mathrm{NH} \mathrm{OHCA}$ cases were shown to have poorer prognostic baseline factors that resulted in poorer outcomes despite having better bystander AED and CPR rates. After adjustments for baseline prognostic factors and resuscitative efforts, NH patients were found to have similar survival-to-discharge rates as the general population regardless of whether they had presumed cardiac or non-cardiac aetiology. In terms of absolute numbers, however, few $\mathrm{NH}$ patients survived with good neurological outcomes $(<1 \%$ or 4 patients in $>5$ years). NH patients also had lower rates of presumed cardiac aetiology or initial shockable rhythm. These findings concurred with those found by previous studies from overseas. ${ }^{20,21}$

In the $4 \mathrm{NH}$ patients who survived with good neurological outcomes, a few observations were made. All of them were well below the median age of 79 years old seen in most $\mathrm{NH}$ residents and had attained ROSC en-route to ED. While all were witnessed arrests, 3 had initial shockable rhythm. These findings suggest that traditional factors associated with good prognosis are relevant even in this population. Some of the good prognostic factors are not known in advance and may not be taken into account during advance care planning (ACP). However, when more data on poor prognostic factors are published in future studies, the findings could lead to a review of current regulations on prehospital termination of resuscitation.

The finding of a low absolute number of survivors with good neurological outcomes does provide some basis to encourage uptake of ACP in NH residents and chronically debilitated individuals, since the take-up rate of ACP has remained anecdotally low. Studies in Japan suggested that NH OHCA residents might have received bystander CPR against their will. ${ }^{9}$ Local studies on end-of-life care found that most 


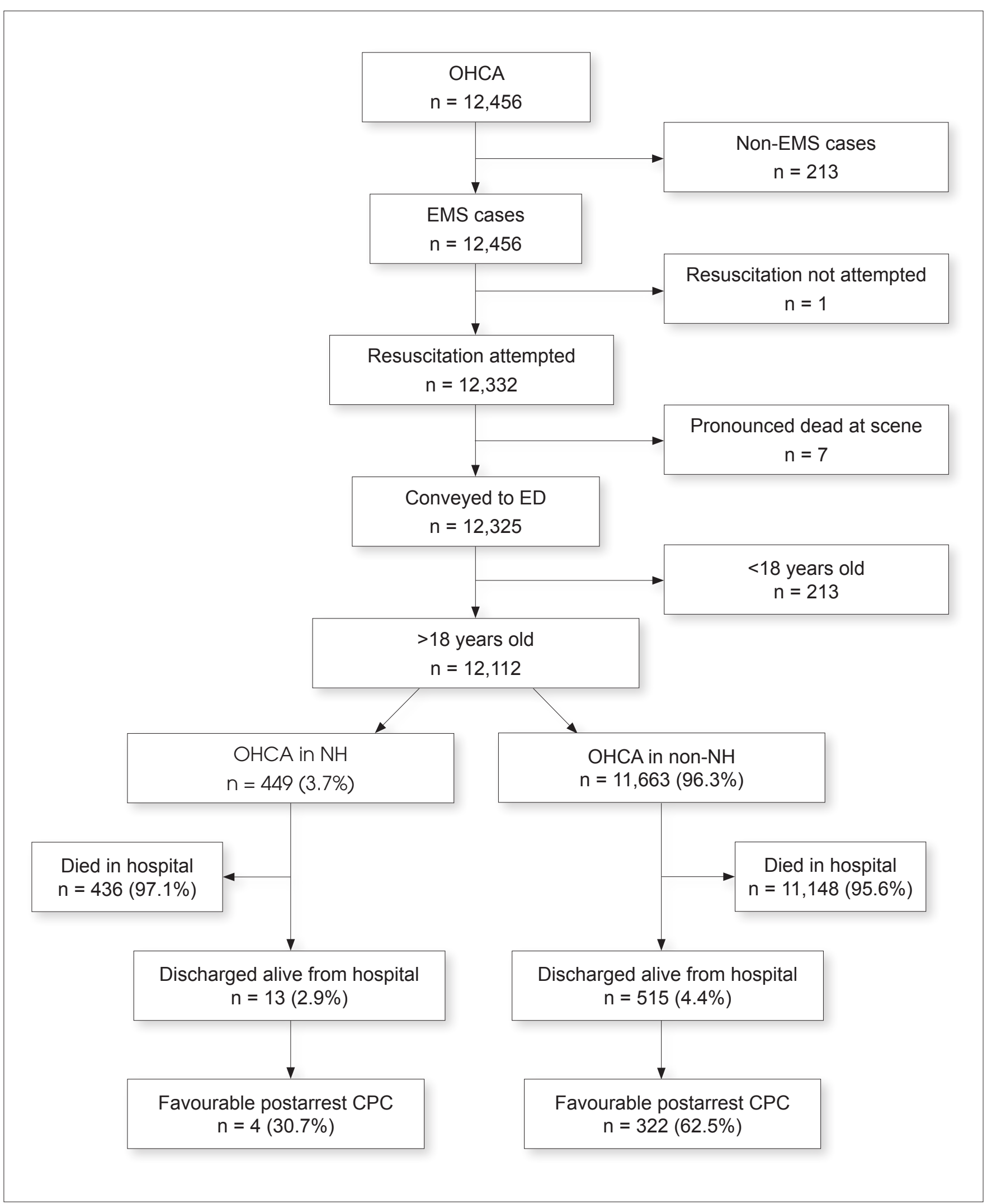

Fig. 1. Flow chart of patient selection process. CPC: Cerebral performance categories; ED: Emergency department; EMS: Emergency medical services; NH: Nursing home; OHCA: Out-of-hospital cardiac arrest 
Table 1. Baseline Characteristics of NH and non-NH Patients with Cardiac Arrest

\begin{tabular}{|c|c|c|c|c|}
\hline Variable & $\begin{array}{l}\text { NH and Non-NH } \\
(\mathrm{n}=12,112)\end{array}$ & $\begin{array}{c}\text { NH } \\
(n=449)\end{array}$ & $\begin{array}{c}\text { Non-NH } \\
(\mathrm{n}=\mathbf{1 1 , 6 6 3 )}\end{array}$ & $P$ Value \\
\hline Median age, years (IQR) & $67(56-79)$ & $79(69-87)$ & $67(55-79)$ & $<0.001$ \\
\hline Gender $(\%)$ & & & & 0.0055 \\
\hline Men & $7872(65.0)$ & $264(58.8)$ & $7608(65.2)$ & \\
\hline Women & $4240(35.0)$ & $185(41.2)$ & $4055(34.8)$ & \\
\hline Ethnicity (\%) & & & & $<0.001$ \\
\hline Chinese & $8265(68.2)$ & $376(83.7)$ & $7889(67.6)$ & \\
\hline Malay & $1848(15.3)$ & $31(6.9)$ & $1817(15.6)$ & \\
\hline Indian & $1317(10.9)$ & $36(8.0)$ & $1281(11.0)$ & \\
\hline Others & $682(5.6)$ & $6(1.3)$ & $675(5.8)$ & \\
\hline \multicolumn{5}{|l|}{ Medical history (\%) } \\
\hline Heart disease & $4460(36.8)$ & $193(43.0)$ & 4267 (36.6) & 0.0070 \\
\hline Diabetes mellitus & $3940(32.5)$ & $169(37.6)$ & $3771(32.3)$ & 0.020 \\
\hline Cancer & $1184(9.8)$ & $35(7.8)$ & $1149(9.9)$ & 0.17 \\
\hline Respiratory disease & $1483(12.2)$ & $76(16.9)$ & $1407(12.1)$ & 0.0026 \\
\hline Renal disease & $1528(12.6)$ & $53(11.8)$ & 1475 (12.6) & 0.70 \\
\hline Stroke & $1600(13.2)$ & $152(33.9)$ & $1448(12.4)$ & $<0.001$ \\
\hline Hypertension & $6586(54.4)$ & $296(65.9)$ & $6290(53.9)$ & $<0.001$ \\
\hline Hyperlipidaemia & $4531(37.4)$ & $201(44.8)$ & $4330(37.1)$ & 0.001 \\
\hline Aetiology of cardiac arrest (\%) & & & & $<0.001$ \\
\hline Presumed cardiac aetiology & $8470(69.9)$ & $277(61.7)$ & $8193(70.2)$ & \\
\hline Others & $3642(30.1)$ & $172(38.3 \%)$ & $3470(29.8)$ & \\
\hline Initial rhythm (\%) & & & & $<0.001$ \\
\hline Shockable & $2162(17.9)$ & $40(8.9)$ & $2122(18.2)$ & \\
\hline Not shockable & $9950(82.1)$ & $409(91.1)$ & $9541(81.8)$ & \\
\hline
\end{tabular}

IQR: Interquartile range; NH: Nursing home

$\mathrm{NH}$ residents preferred not to undergo aggressive resuscitation than the non-NH population. ${ }^{10,22,23}$ Surveys of other communities also showed that many patients overestimated the survival rate following CPR and were therefore more keen to undergo CPR. ${ }^{10}$ Early establishment of care goals can help $\mathrm{NH}$ residents to make deliberate and informed decisions and reduce unwanted or futile resuscitation attempts that would otherwise go against their wishes and consume healthcare resources.

In this study, more NH (74\%) than non-NH (34\%) residents received bystander CPR. Assuming that $\mathrm{NH}$ staff are trained in basic cardiac life support to administer resuscitation in OHCA patients in a timely manner, it then follows that, for various reasons, about $26 \%$ of NH residents did not receive bystander CPR. Since some NH may lack staff, it would be difficult for them to provide bystander CPR. ${ }^{24-6}$ However, when $\mathrm{NH}$ residents already had predefined care goals and do-not-resuscitate orders, they should not be transported to hospitals for resuscitation. Since data on ACP in $\mathrm{NH}$ residents was lacking and a conclusion could not be made, the finding of a low bystander CPR rate in these patients did imply either inadequate resuscitation of those without ACP or inappropriate use of ED for death certification purposes rather than resuscitation. 
Table 2. Outcomes and Resuscitation Factors in NH and non-NH Patients with Cardiac Arrest

\begin{tabular}{|c|c|c|c|c|}
\hline Variable & $\begin{array}{l}\text { NH and Non-NH } \\
\quad(n=12,112)\end{array}$ & $\begin{array}{c}\text { NH } \\
(n=449)\end{array}$ & $\begin{array}{c}\text { Non-NH } \\
(n=11,663)\end{array}$ & $P$ Value \\
\hline Arrest witnessed by $(\%)$ & & & & 0.14 \\
\hline Not witnessed & 4818 (39.8) & 199 (44.3) & 4619 (39.6) & \\
\hline Bystander & $6246(51.6)$ & $214(47.7)$ & $6032(51.7)$ & \\
\hline EMS & $1048(8.7)$ & $36(8.0)$ & $1012(8.7)$ & \\
\hline Bystander CPR (\%) & & & & $<0.001$ \\
\hline Yes & $5287(43.7)$ & $333(74.2)$ & $4954(42.5)$ & \\
\hline No & $6825(56.3)$ & $116(25.8)$ & $6709(57.5)$ & \\
\hline Bystander AED applied (\%) & & & & $<0.001$ \\
\hline No & $11,752(97.0)$ & $411(91.5)$ & $11,341(97.2)$ & \\
\hline Prehospital defibrillation (\%) & & & & $<0.001$ \\
\hline Yes & $3158(26.1)$ & $61(13.6)$ & $3097(26.6)$ & \\
\hline No & $8954(73.9)$ & $388(86.4)$ & $8566(73.4)$ & \\
\hline \multicolumn{5}{|l|}{ Median response time in minutes (IQR) } \\
\hline Time of arrest to time of call (call after arrest) & $5.7(2.3-12.3)$ & $5.5(2.4-11.9)$ & $5.7(2.3-12.4)$ & 0.68 \\
\hline Time of arrest to time of call (call before arrest) & $6.2(1.6-16.5)$ & $6.0(2.9-12.8)$ & $6.2(1.6-16.7)$ & 0.94 \\
\hline $\begin{array}{l}\text { Time of call to time of arrival at scene by EMS } \\
\text { (response time) }\end{array}$ & $8.7(6.7-11.3)$ & $7.7(6.0-10.0)$ & $8.7(6.7-11.3)$ & $<0.001$ \\
\hline $\begin{array}{l}\text { Time of call to time of arrival at scene by first bystander } \\
\text { (response time) }\end{array}$ & $8.2(6.4-10.5)$ & $8.5(6.0-10.0)$ & $8.2(6.4-10.5)$ & 0.72 \\
\hline $\begin{array}{l}\text { Time of arrival to time of departure from scene by EMS } \\
\text { (scene time) }\end{array}$ & $17.1(13.7-20.9)$ & $15.7(12.9-19.8)$ & $17.1(13.8-21.0)$ & $<0.001$ \\
\hline $\begin{array}{l}\text { Time of departure from location to time of arrival at hospital } \\
\text { (en-route time) }\end{array}$ & $9.3(6.5-12.7)$ & $9.7(6.4-13.5)$ & $9.3(6.5-12.7)$ & 0.48 \\
\hline Time of call to first ROSC (en-route or at ED) & $42.6(33.0-51.5)$ & $40.0(31.1-49.4)$ & $42.7(33.3-51.6)$ & 0.041 \\
\hline Time of arrival (earlier than EMS and FR) to CPR & $3.0(1.8-4.7)$ & $2.9(1.8-4.3)$ & $3.0(1.8-4.7)$ & 0.2218 \\
\hline Time of arrival (earlier than EMS and FR) to AED use & $4.6(3.1-6.4)$ & $4.0(2.9-5.6)$ & $4.6(3.1-6.5)$ & $<0.001$ \\
\hline Time of arrival (earlier than EMS and FR) to first shock & $5.8(3.6-10.5)$ & $6.2(4.0-12.2)$ & $5.8(3.6-10.4)$ & 0.54 \\
\hline \multicolumn{5}{|l|}{ Patient outcome $(\%)$} \\
\hline ROSC (en-route or at ED) & $4012(33.1)$ & $126(28)$ & $3886(33)$ & 0.021 \\
\hline Survival to admission & $2164(17.9)$ & $50(11.1)$ & $2114(18.1)$ & $<0.001$ \\
\hline Survival to discharge or at 30 days & $528(4.4)$ & $13(2.9)$ & $515(4.4)$ & 0.16 \\
\hline Favourable postarrest CPC (1 and 2) & $326(2.7)$ & $4(0.9)$ & $322(2.8)$ & 0.038 \\
\hline Favourable postarrest OPC (1 and 2 ) & $319(2.6)$ & $4(0.9)$ & $315(2.7)$ & 0.041 \\
\hline
\end{tabular}

AED: Automated external defibrillator; CPC: Cerebral performance categories; CPR: Cardiopulmonary resuscitation; DNAR: Do not attempt resuscitation; EMS: Emergency medical services; ED: Emergency department; FR: First Responder ; IQR: Interquartile range; NH: Nursing home; ROSC: Return of spontaneous circulation; OPC: Overall performance categories 


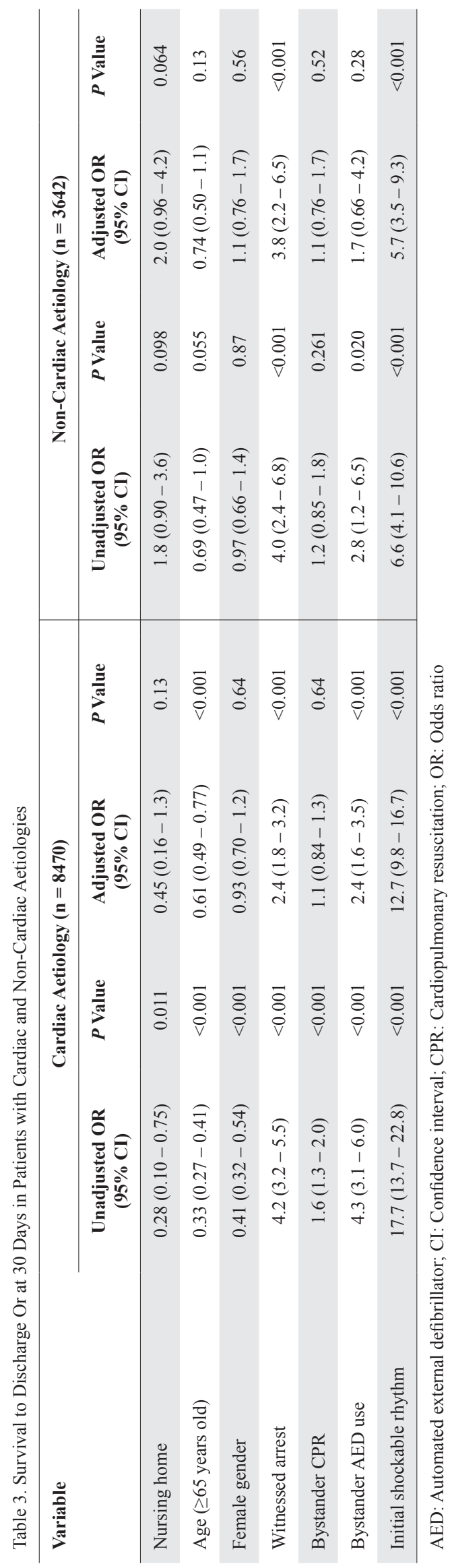

Additionally, $44.3 \%$ of NH OHCA were unwitnessed, suggesting a need for protocols to be drawn up in $\mathrm{NH}$ for timely recognition of arrest events. ${ }^{27}$ However, the $\mathrm{NH}$ population is generally more frail and may not be communicative at baseline, and this makes it difficult to observe a change in their clinical status. This issue is further compounded by the lack of nursing staff. ${ }^{24}$ Some solutions may include adjustments in staff and manpower requirements and appropriate use of patient monitoring devices as part of early warning systems. ${ }^{28}$

This study has several limitations. First, the PAROS registry did not capture neurological status of patients prior to arrest and this limited interpretation of the results since a change in status from baseline could provide insights for ACP. Second, the registry did not capture information on prior care preferences such as Advance Medical Directive (AMD). Finally, although the registry had collected information about the resuscitation process, intangible data on the quality of resuscitation was not captured since healthcare providers might be hesitant to vigorously resuscitate patients whom they believed had poor outcomes. Since this study only examined factors that were associated with survival and favourable neurological outcomes, quality of life measures among survivors were not evaluated. Recent studies had shown that OHCA survivors tended to experience cognitive and emotional issues. ${ }^{29-31}$ Since NH residents were often admitted from a lack of social support, further study is needed on the cognitive and emotional needs of this population. Local studies had also found that ACP was often undertaken in acute hospitals. Hence, the issue of an uptake in ACP and AMD in NH residents could be further examined. ${ }^{22}$ Meaningful interpretation of data from cardiac arrest registries may be enhanced when information on neurological status prior to arrest and prior care preferences is captured.

\section{Conclusion}

OHCA patients in $\mathrm{NH}$ had similar survival rates as non-NH patients; however, they had poorer neurological outcomes. The incidence of NH survivors with good neurological outcomes is $<1 \%$. These findings can inform ACP in NH residents to help them make informed decisions on their care goals and plans. 


\section{Acknowledgements}

The authors would like to thank the late Susan Yap and Maeve Pek from Department of Emergency Medicine, Singapore General Hospital, and Noor Azuin and Nurul Asyikin from the Unit for Prehospital Emergency Care, Singapore General Hospital, for their contributions and support to the Singapore OHCA registry, and all other PAROS investigators that contributed to the study. This study was supported by grants from the National Medical Research Council, Singapore (NMRC/CSA/024/2010 and NMRC/CSA/0049/2013) and Ministry of Health, Singapore (HSRG/0021/2012). Dr Andrew FW Ho was supported by Khoo Clinical Scholars Programme, Khoo Pilot Award (KP/2019/0034), Duke-NUS Medical School and National Medical Research Council (NMRC/CSSeedfd/012/2018).

\section{Conflict of Interest}

Dr Marcus EH Ong reported funding from Zoll Medical Corporation for a study involving mechanical cardiopulmonary resuscitation devices; grants from Laerdal Foundation, Laerdal Medical and Ramsey Social Justice Foundation to fund the Pan-Asian Resuscitation Outcomes Study; an advisory relationship with Global Healthcare Singapore, a commercial entity that manufactures cooling devices; and funds from Laerdal Medical on an observation programme to its Community Cardiopulmonary Training Centre Research Program in Norway.

\section{REFERENCES}

1. Ong MEH, Perkins GD, Cariou A. Out-of-hospital cardiac arrest: prehospital management. Lancet 2018;391:980-8.

2. Lai H, Choong CV, Fook-Chong S, Ng YY, Finkelstein EA, Haaland B, et al. Interventional strategies associated with improvements in survival for out-of-hospital cardiac arrests in Singapore over 10 years. Resuscitation 2015;89:155-61.

3. Nadarajan GD, Tiah L, Ho AFW, Azazh A, Castren MK, Chong $\mathrm{SL}$, et al. Global resuscitation alliance utstein recommendations for developing emergency care systems to improve cardiac arrest survival. Resuscitation 2018;132:85-9.

4. Libungan B, Lindqvist J, Strömsöe A, Nordberg P, Hollenberg J, Albertsson $\mathrm{P}$, et al. Out-of-hospital cardiac arrest in the elderly: a large-scale population-based study. Resuscitation 2015;94:28-32.

5. Pape M, Rajan S, Hansen SM, Mortensen RN, Riddersholm S, Folke F, et al. Survival after out-of-hospital cardiac arrest in nursing homes - a nationwide study. Resuscitation 2018;125:90-8.

6. Benkendorf R, Swor RA, Jackson R, Rivera-Rivera EJ, Demrick A. Outcomes of cardiac arrest in the nursing home: destiny or futility? Prehosp Emerg Care 1997;1:68-72.

7. Hirlekar G, Karlsson T, Aune S, Ravn-Fischer A, Albertsson P, Herlitz J, et al. Survival and neurological outcome in the elderly after in-hospital cardiac arrest. Resuscitation 2017;118:101-6.

8. Funada A, Goto Y, Maeda T, Tada H, Teramoto R, Tanaka Y, et al. Prehospital predictors of neurological outcomes in out-of-hospital cardiac arrest patients aged 95 years and older: a nationwide population-based observational study. J Cardiol 2017;69:340-4.

9. Okabayashi S, Matsuyama T, Kitamura T, Kiyohara K, Kiguchi T, Nishiyama C, et al. Outcomes of patients 65 years or older after out-of-hospital cardiac arrest based on location of cardiac arrest in Japan. JAMA Netw Open 2019;2:e191011.
10. Zijlstra TJ, Leenman-Dekker SJ, Oldenhuis HKE, Bosveld HEP, Berendsen AJ. Knowledge and preferences regarding cardiopulmonary resuscitation: a survey among older patients. Patient Educ Couns 2016;99:160-3.

11. Becker LB, Aufderheide TP, Geocadin RG, Callaway CW, Lazar RM, Donnino MW, et al. Primary outcomes for resuscitation science studies: a consensus statement from the American Heart Association. Circulation 2011;124:2158-77.

12. Ong MEH, Shin SD, Tanaka H, Ma MHM, Khruekarnchana P, Hisamuddin N, et al. Pan-Asian Resuscitation Outcomes Study (PAROS): rationale, methodology, and implementation. Acad Emerg Med 2011;18:890-7.

13. Cummins RO, Chamberlain DA, Abramson NS, Allen M, Baskett PJ, Becker L, et al. Recommended guidelines for uniform reporting of data from out-of-hospital cardiac arrest: the Utstein style. A statement for health professionals from a task force of the American Heart Association, the European Resuscitation Council, the Heart and Stroke Foundation of Canada, and the Australian Resuscitation Council. Circulation 1991;84:960-75.

14. McNally B, Stokes A, Crouch A, Kellermann AL. CARES: Cardiac Arrest Registry to Enhance Survival. Ann Emerg Med 2009;54:674-83.

15. Ho AFW, Hao Y, Pek PP, Shahidah N, Yap S, Ng YY, et al. Outcomes and modifiable resuscitative characteristics amongst pan-Asian out-of-hospital cardiac arrest occurring at night. Medicine (Baltimore) 2019;98:e14611.

16. Wah W, Wai KL, Pek PP, Ho AFW, Alsakaf O, Chia MYC, et al. Conversion to shockable rhythms during resuscitation and survival for out-of hospital cardiac arrest. Am J Emerg Med 2017;35:206-13.

17. Ng YY, Wah W, Liu N, Zhou SA, Ho AFW, Pek PP, et al. Associations between gender and cardiac arrest outcomes in pan-Asian out-ofhospital cardiac arrest patients. Resuscitation 2016;102:116-21.

18. Tan TXZ, Hao Y, Ho AFW, Shahidah N, Yap S, Ng YY, et al. Inter-hospital variations in resuscitation processes and outcomes of out-of-hospital cardiac arrests in Singapore. J Emerg Crit Care Med 2019;3:21

19. Ho AFW, Sim ZJ, Shahidah N, Hao Y, Ng YY, Leong BSH, et al. Barriers to dispatcher-assisted cardiopulmonary resuscitation in Singapore. Resuscitation 2016;105:149-55.

20. Carew HT, Zhang W, Rea TD. Chronic health conditions and survival after out-of-hospital ventricular fibrillation cardiac arrest. Heart 2007;93:728-31.

21. Beesems SG, Blom MT, van der Pas MHA, Hulleman M, van de Glind EMM, van Munster BC, et al. Comorbidity and favorable neurologic outcome after out-of-hospital cardiac arrest in patients of 70 years and older. Resuscitation 2015;94:33-9.

22. Tan WS, Bajpai R, Ho AHY, Low CK, Car J. Retrospective cohort analysis of real-life decisions about end-of-life care preferences in a Southeast Asian country. BMJ Open 2019; 9:e024662.

23. Ng CWL, Cheong SK, Govinda Raj A, Teo WSK, Leong IYO. End-of-life care preferences of nursing home residents: results of a cross-sectional study. Palliat Med 2016;30:843-53.

24. Laging B, Kenny A, Bauer M, Nay R. Recognition and assessment of residents' deterioration in the nursing home setting: a critical ethnography. J Clin Nurs 2018;27:1452-63. 
25. Ho AFW, Liu Z, Wah W, Fook-Chong S, Pek PP, Lo HY, et al. Evaluation of culture-specific popular music as a mental metronome for cardiopulmonary resuscitation: a randomised crossover trial. Proc Singapore Healthc 2019:28:159-66.

26. Zhou SA, Ho AFW, Liu N, Ong MEH, Zheng Y, Pek PP, et al. Asian first responder's tolerance for sustaining chest compressions during resuscitation. Invest Clin 2019;60:376-82.

27. Little S, Rodgers G, Fitzpatrick JM. Managing deterioration in older adults in care homes: a quality improvement project to introduce an early warning tool. Br J Community Nurs 2019;24:58-66.

28. Liu N, Zhang Z, Ho AFW, Ong MEH. Artificial intelligence in emergency medicine. J Emerg Crit Care Med 2018;2:82.
29. Viktorisson A, Sunnerhagen KS, Pöder U, Herlitz J, Axelsson AB. Well-being among survivors of out-of-hospital cardiac arrest: a cross-sectional retrospective study in Sweden. BMJ Open 2018;8:e021729.

30. Bohm M, Lilja G, Finnbogadóttir H, Cronberg T, Undén J, Friberg $\mathrm{H}$, et al. Detailed analysis of health-related quality of life after out-of-hospital cardiac arrest. Resuscitation 2019; 135:197-204.

31. Boyce LW, Goossens PH, Moulaert VR, Pound G, van Heugten CM. Out-of-hospital cardiac arrest survivors need both cardiological and neurological rehabilitation! Curr Opin Crit Care 2019;25:240-3. 